\title{
Synergistic Effect of Nanophotocatalysis and Nonthermal Plasma on the Removal of Indoor HCHO
}

\author{
Yuanwei Lu, ${ }^{1}$ Dinghui Wang, ${ }^{2}$ Yuting Wu, ${ }^{1}$ Chongfang Ma, ${ }^{1}$ \\ Xingjuan Zhang, ${ }^{3}$ and Chunxin Yang ${ }^{3}$ \\ ${ }^{1}$ Key Laboratory of Enhanced Heat Transfer and Energy Conservation of Ministry of Education, \\ College of Environmental and Energy Engineering, Beijing University of Technology, Beijing 100022, China \\ ${ }^{2}$ Research Institute Guodian United Power Technology Co, Ltd, Beijing 100039, China \\ ${ }^{3}$ School of Aeronautic Science and Engineering, Beijing University of Aeronautics and Astronautics, Beijing 100191, China \\ Correspondence should be addressed to Yuanwei Lu, luyuanwei910@hotmail.com
}

Received 28 October 2011; Revised 20 December 2011; Accepted 20 December 2011

Academic Editor: Jiaguo Yu

Copyright (๑) 2012 Yuanwei Lu et al. This is an open access article distributed under the Creative Commons Attribution License, which permits unrestricted use, distribution, and reproduction in any medium, provided the original work is properly cited.

Photocatalysis is an effective method of air purification at the condition of a higher pollutant concentration. However, its wide application in indoor air cleaning is limited due to the low level of indoor air contaminants. Immobilizing the nanosized $\mathrm{TiO}_{2}$ particles on the surface of activated carbon filter $\left(\mathrm{TiO}_{2} / \mathrm{AC}\right.$ film $)$ could increase the photocatalytic reaction rate as a local high pollutant concentration can be formed on the surface of $\mathrm{TiO}_{2}$ by the adsorption of AC. However, the pollutant removal still decreased quickly with the increase in flow velocity, which results in a decrease in air treatment capacity. In order to improve the air treatment capacity by the photocatalytic oxidation (PCO) method, this paper used formaldehyde (HCHO) as a contaminant to study the effect of combination of PCO with nonthermal plasma technology (NTP) on the removal of HCHO. The experimental results show that $\mathrm{HCHO}$ removal is more effective with line-to-plate electrode discharge reactor; the HCHO removal and the reaction rate can be enhanced and the amount of air that needs to be cleaned can be improved. Meanwhile, the results show that there is the synergistic effect on the indoor air purification by the combination of PCO with NTP.

\section{Introduction}

Indoor air quality has become an important issue in recent years. Research shows that the level of indoor contaminants is 2-10 times higher than that in outdoor. In general, indoor volatile organic compounds (VOCs) coming from office products, insulting materials, synthetic furniture, press wood, and so forth have the relations to adverse health effects such as allergic reactions, headache, eye, nose, and throat irritation, and even cancer. The traditional method of cleaning indoor contaminants is physical adsorption, but the adsorbent has the properties of adsorption saturation and needs to be alternated periodically.

Photocatalysis is a promising technology for indoor air purification, which has been used in many fields since the research of photocatalytic water split on $\mathrm{TiO}_{2}$ electrodes was reported in 1972 [1-10]. This photocatalytic method is effective in the case of a higher pollutant concentration, but its wide application is limited due to the low level of in- door air contaminants. In order to improve the removal of pollutant in indoor air, many researches have investigated the photodegradation of indoor air pollutants by loading $\mathrm{TiO}_{2}$ catalysts on activated carbon filter $\left(\mathrm{TiO}_{2} / \mathrm{AC}\right.$ film $)$ to increase the local concentration of pollutants on the surface of catalyst [11-20]. However, the contaminants removal still decreased sharply with the rise in flow velocity, especially at the low level of indoor pollutant concentration. Therefore, it is needed to improve the reaction rate at higher flow velocity for the flow velocity will directly affect the amount of air to be cleaned, which is important to the practical application of this method.

Nonthermal plasma (NTP) technology has been widely studied for VOCs oxidation. It has been reported as a most hopeful air cleaning technology to remove toxic volatile contaminants in air. The NTP approach is energy-efficient and is capable of removing various indoor pollutants simultaneously. Atmospheric plasma discharges generate highenergy electrons, while the background gas remains close to 
room temperature $[21,22]$. The energetic electrons excite, dissociated, and ionize gas molecules producing chemically active species (atomic oxygen, hydroxyl radicals, ozone, etc.). These species are capable of oxidizing volatile organic compounds. Recently, activated carbon, catalyst, and nonthermal plasma are combined together as a new treatment method to solve the problem of environmental pollution [23]. Studies [24] have proved that the atmospheric electric discharges emit radiation with wavelength between 290 and $400 \mathrm{~nm}$. This UV emission range lies within the absorption spectrum range of $\mathrm{TiO}_{2}$. Therefore, placing photocatalytic material, such as semiconductor $\mathrm{TiO}_{2}$, into the plasma zone can improve the photocatalytic efficiency of air purification because the photocatalytic reaction can be triggered by both the highenergy plasma species and the UV emission during the plasma discharge. At the same time, the directional migration of electrons in the high voltage electric field can decrease the recombination of the electron-hole pairs in the process of photocatalysis. However, the effects of the plasma discharge configuration, flow velocity and humidity on the removal of contaminants by the combination of NTP with PCO are still scarce.

The objective of this study is to investigate the effect of combination of PCO with NTP on the removal of indoor $\mathrm{HCHO}$. The effects of plasma discharge configuration, the applied voltage, the flow velocity and the humidity on the $\mathrm{HCHO}$ removal were studied. The reaction rate and $\mathrm{HCHO}$ removal were used as two parameters to evaluate $\mathrm{HCHO}$ removal efficiency.

\section{Experiment}

2.1. Reagents and Catalyst Preparation. The reactant gas $\mathrm{HCHO}$ was acquired from an $\mathrm{HCHO}$ penetration equipment. The detailed experimental setup has been described elsewhere [12].

$\mathrm{TiO}_{2}$ (Degussa p-25) was used as the photocatalyst. Water suspension with $5 \mathrm{wt} \%$ of $\mathrm{TiO}_{2}$ was coated on a piece of honeycomb activated carbon (AC) filter by the dipping method and then was calcined at $180^{\circ} \mathrm{C}$ for $1 \mathrm{~h}$ with a ramp of $3^{\circ} \mathrm{C} / \mathrm{min}$ to form the $\mathrm{TiO}_{2}$-coated film (i.e., $\mathrm{TiO}_{2} / \mathrm{AC}$ film). The area of the netlike AC film was $75 \mathrm{~mm} \times 25 \mathrm{~mm}$. The amount of $\mathrm{TiO}_{2}$ loaded was determined by the weight difference before and after the coating procedure. The weight of $\mathrm{TiO}_{2}$ loaded was about 0.12 g. Figure 1 shows the $\mathrm{TiO}_{2}$ films coated on the honeycomb AC filter.

2.2. Electrode Configuration of Plasma Discharge System. Because the indoor $\mathrm{HCHO}$ concentration is low relative to that coming from industry, the indoor contaminants removal method should have properties such as low energy consumption, no undesired intermediate products, safe use, simple configuration and being used at room temperature and atmospheric pressure. Comparing the characteristics of different plasma methods, the direct current (DC) streamer discharge mode can satisfy the above properties. Pine-toplate and wire-to-plate electrode configuration were designed for producing plasma, as shown in Figures 2 and 3. The

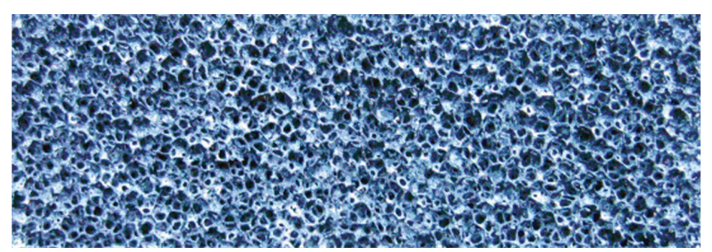

Figure 1: $\mathrm{TiO}_{2} / \mathrm{AC}$ film.

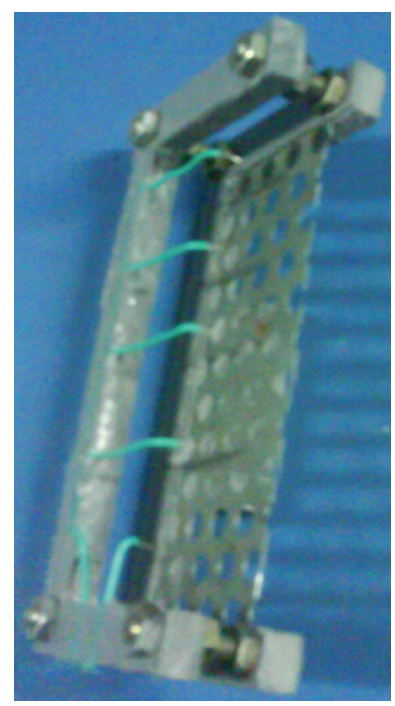

Figure 2: Pine-to-plate electrode configuration.

two-electrode configuration adopted anode discharge to produce plasmas. The anode pine (or wire) was connected with the positive side of the high-voltage DC power and the cathode plate was connected with negative (ground) electrode. When the DC high-voltage power was turned on, the NTP will be produced between anode needle (or wire) and cathode plate.

2.3. Plasma and $\mathrm{TiO}_{2} / \mathrm{AC}$ Hybrid Configuration. Figure 4 shows the hybrid configuration of plasma and catalyst film. The $\mathrm{TiO}_{2} / \mathrm{AC}$ film was placed between the wire and the plate electrode. Using such a combination of PCO with NTP, HCHO can be fully degraded for the $\mathrm{HCHO}$ and its secondary products can be absorbed on the surface of $\mathrm{TiO}_{2}$ by the adsorption of active carbon until it was completely oxidized into carbon dioxide and water. Also, the local higher $\mathrm{HCHO}$ concentration generated by the adsorption of active carbon on the $\mathrm{TiO}_{2}$ surface can improve the removal of HCHO.

2.4. Experimental Section. The schematic experimental system is detailed [12], and the configuration of the experimental section is illustrated in Figure 5. The reactant gas with a constant concentration, humidity, and reaction flow velocity can be formed in the experimental system [12]. The reactant gas flowed through the reactor and was decomposed in it. The reactor in the experimental section was made of stainless steel with a volume of $195 \mathrm{~mL}(3 \mathrm{H} \times 13 \mathrm{~L} \times 5 \mathrm{~W} \mathrm{~cm})$. 


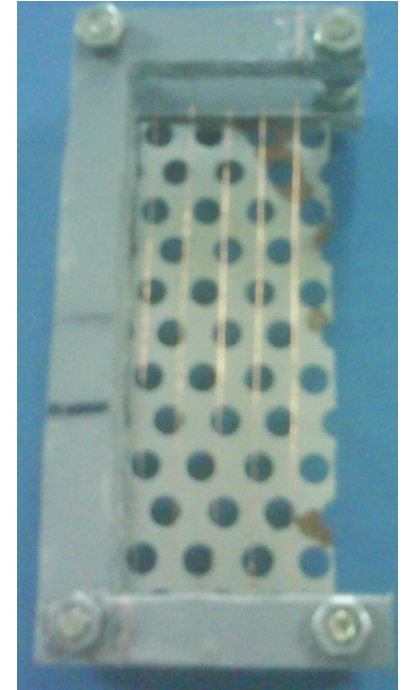

FigURE 3: Wire-to-plate electrode configuration.

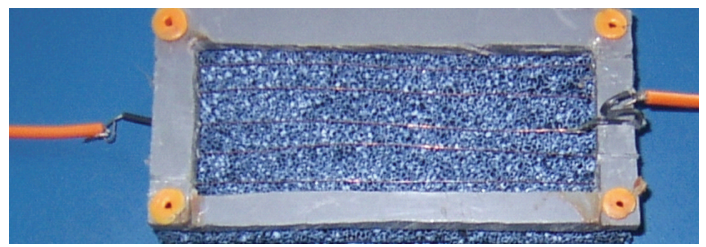

FIgURe 4: The hybrid configuration and catalyst film.

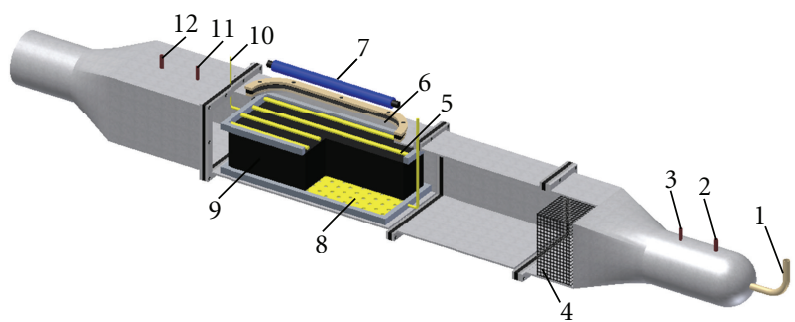

Figure 5: Experimental section. (1) Reactant stream inlet. (2) Zero air inlet (3) Humidified air inlet. (4) Mixer. (5) Electrode wire (6) Quartz glass window. (7) UV lamp (8) Electrode plate. (9) TiO2 film. (10) Lead thread. (11) Sampling port. (12) Humidity and temperature sampling port.

The upper wall of the reactor is made of quartz for light entrance. Illumination was provided by an $8 \mathrm{~W}$ UV lamp, which emits light at a primary wavelength of $365 \mathrm{~nm}$ and was horizontally placed on the upper of the quartz window of the reactor. The UV light intensity of $1180 \mu \mathrm{W} / \mathrm{cm}^{2}$ was determined by a UV meter (UV-A) in all of the experiments. The $\mathrm{TiO}_{2}$ film was inserted between the plasma electrodes to take advantage of the UV emission coming from the plasma discharge. The one-pass removal efficiency of $\mathrm{HCHO}$ in plasma discharge system with and without $\mathrm{TiO}_{2}$ film was studied. There is a fully developed region before the

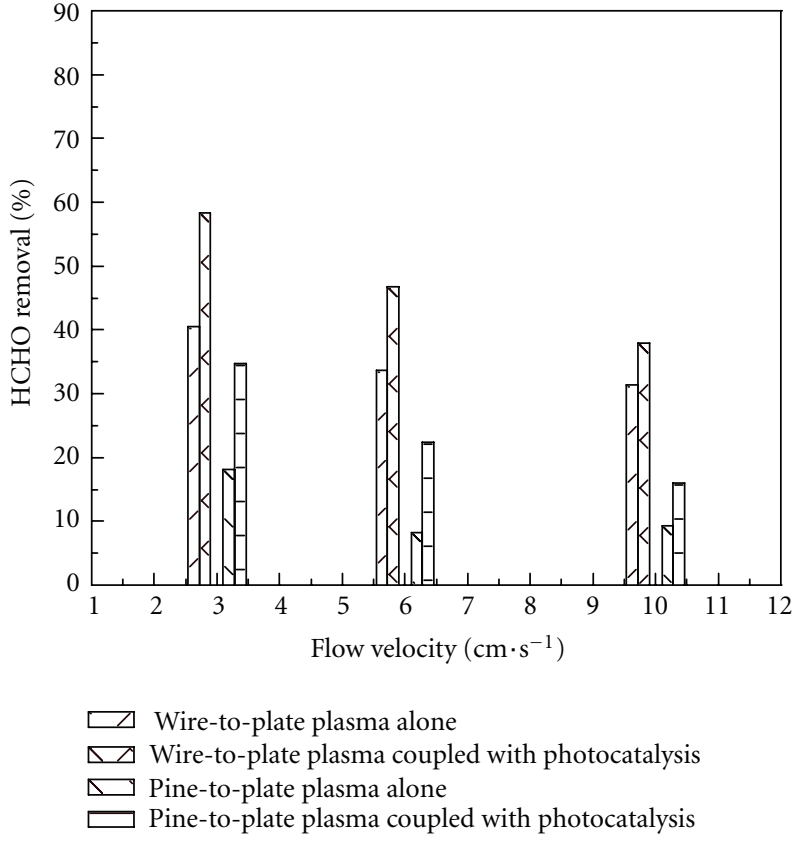

Figure 6: The removal of $\mathrm{HCHO}$ varies with flow velocity by different corona discharge.

reactor to form a stable air stream, and a mixer was placed inside it to mix the reactant gas well. The sampling port was set at the end of reactor. After the inlet concentration equaled to the outlet concentration, that is to say, the experimental system reached equilibrium (about 1 to $2 \mathrm{~h}$ ), the $\mathrm{HCHO}$ concentration, temperature, and humidity in experimental system were recorded as an initial data. Then the UV lamp and the DC high-voltage power were turned on and the HCHO removal reaction was initiated. After $\mathrm{HCHO}$ concentration at the reactor outlet did not change with time, the concentration, temperature, and humidity were recorded again. Then the degradation of $\mathrm{HCHO}$ was ended and the reaction product mixture was collected. The experiments were carried out at room temperature, and under atmospheric pressure. The $\mathrm{HCHO}$ concentration was measured with the $\mathrm{HCHO}$ analyzer 4160 type (measure accuracy of $\pm 2.0 \%$ of reading), which was produced by the American Interscan Corporation. The temperature and humidity were measured by a Vaisala HUMICAP indicator HMI41 and probe type sensor HMP46 (at $20^{\circ} \mathrm{C}$, measure accuracy of $\pm 1.0 \% \mathrm{RH}$ at the humidity range of $0 \sim 90 \% \mathrm{RH}$ and of $\pm 1.0 \% \mathrm{RH}$ at the humidity range of $90 \sim 100 \% \mathrm{RH}$ ).

\section{Results and Discussions}

3.1. Optimal Electrode Configuration of NTP Discharge. Figure 6 shows the HCHO removal by pine-to-plate and wire-to-plate corona discharge with or without $\mathrm{TiO}_{2}$ photocatalyst at different flow velocity with initial HCHO concentration $1.19 \mathrm{mg} / \mathrm{m}^{3}$. The HCHO removal is defined as

$$
\text { HCHO removal }(\%)=\frac{100\left(C_{\text {in }}-C_{\text {out }}\right)}{C_{\text {in }}},
$$



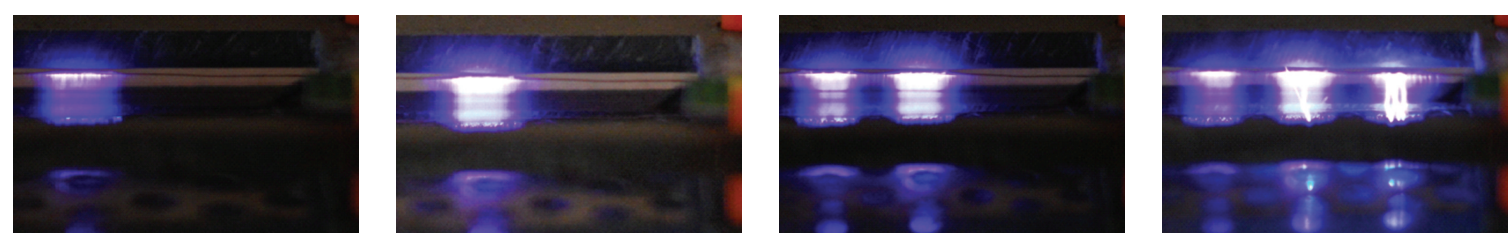

(a)
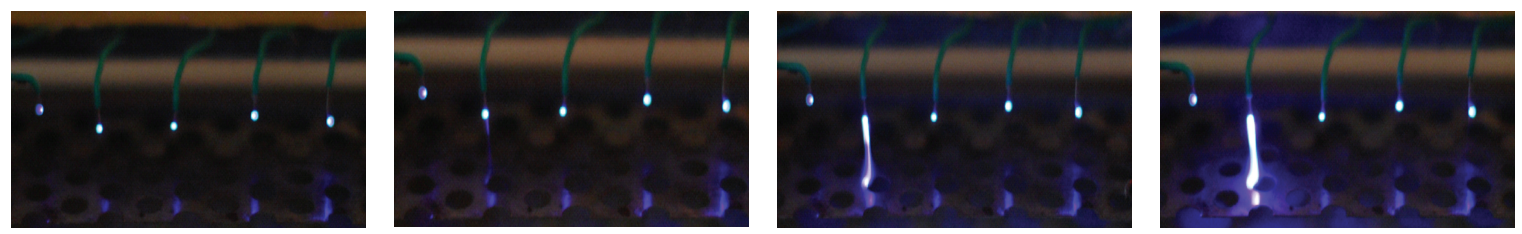

(b)

FIGURE 7: Corona discharge variation with the increase of applied voltage for the different electrode system. (a) Corona discharge variation with the increase in applied voltage for the line-to-plate electrode system. (b) Corona discharge variation with the increase in applied voltage for the pine-to-plate electrode system.

where $C_{\text {in }}$ and $C_{\text {out }}$ are the initial concentration and the steady outlet concentration $\left(\mathrm{mg} / \mathrm{m}^{3}\right)$, respectively. It can be seen that the HCHO removal with wire-to-plate electrode discharge configuration was higher than that with pine-toplate configuration. For example, the removal of $\mathrm{HCHO}$ was only $18.2 \%$ by the pine-to-plate plasma discharge configuration but nearly $41 \%$ by the wire-to-plate discharge at flow velocity of $3 \mathrm{~cm} / \mathrm{s}$. However, when the plasma discharge coupled with $\mathrm{TiO}_{2}$ film the $\mathrm{HCHO}$ removal can be enhanced significantly. As shown in Figure 6, the HCHO removal reached nearly $60 \%$ when wire-to-plate plasma discharge coupled with photocatalysis and about $35 \%$ by combination of pine-to-plate plasma discharge with photocatalysis at the same flow velocity. Apparently, the wire-to-plate discharge configuration has a higher $\mathrm{HCHO}$ removal. The reason can be explained obviously by the streamer discharge photos of different electrode configuration, as shown in Figure 7. The photos from left to right in Figure 7 show the electrode discharge intensity varying with the increase in applied voltage. It can be seen that the streamer discharge propagated from the wire (or the tip of pine) electrode to plate electrode and its length and luminescence intensity increased with the increase in applied voltage. These streamers bridge the gap with flamelike discharge pattern and cover the surface of the catalyst. The wire-to-plate corona discharge has higher luminescence intensity than that of the pineto-plate discharge when the discharge voltage increased from the lower to the breakdown voltage. So the wire-toplate discharge system has higher removal of $\mathrm{HCHO}$ than that in the pine-to-plate discharge system. Also the in situ oxidative species $\left({ }^{\circ} \mathrm{HO}\right)$ can be produced during the NTP production, which can decompose the low-concentration organic compounds. At same time, some physical effects, such as strong fields and streamer (including ultraviolet (UV) light), can also enhance the photocatalytic removal of HCHO during corona discharge process. Therefore, the removal of $\mathrm{HCHO}$ can be improved by the combination of plasma with $\mathrm{TiO}_{2}$ photocatalysis.

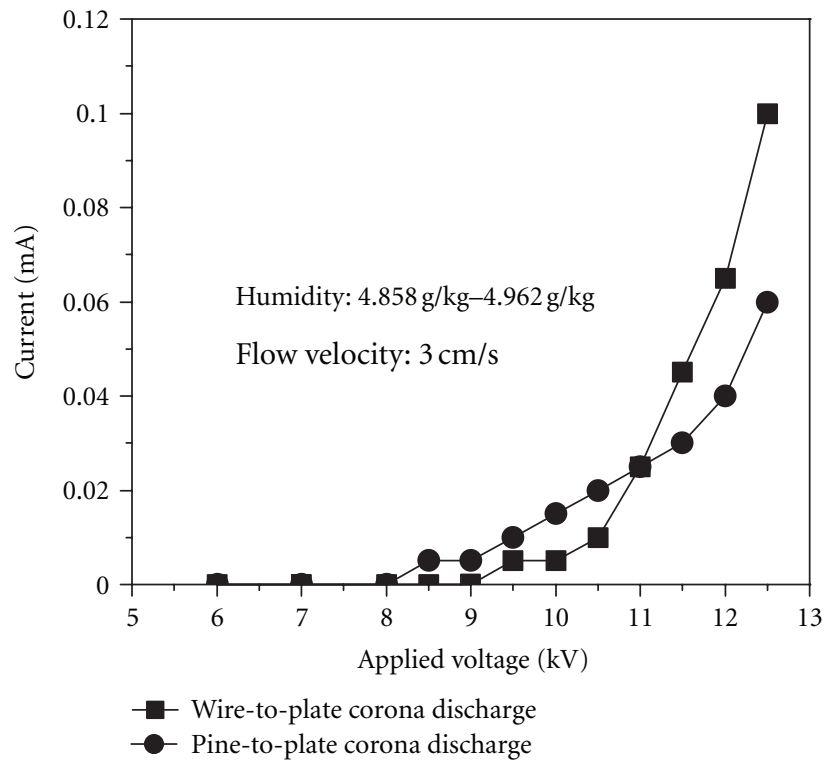

FIGURE 8: Corona current as a function of applied voltage.

The higher performance of the wire-to-plate electrode structure can also be explained by the time-average currentapplied voltage characteristics, as shown in Figure 8. It can be seen that corona current was very small when applied voltage is less than $8 \mathrm{KV}$. At first, corona current generated by pine-to-plate discharge was greater than that generated by the wire-to-plate discharge with the increase in applied voltage. With the further increase in applied voltage, the corona current from wire-to-plate discharge increased sharply, and exceeded the corona current from the pine-toplate discharge. The corona current was $0.1 \mathrm{~mA}$ in wire-toplate discharge system at the applied voltage of $12.5 \mathrm{KV}$ and only $0.06 \mathrm{~mA}$ in the needle-to-plate discharge system. From the above analysis, one can conclude that the wire-to-plate electrode system is effective for the removal of HCHO. 


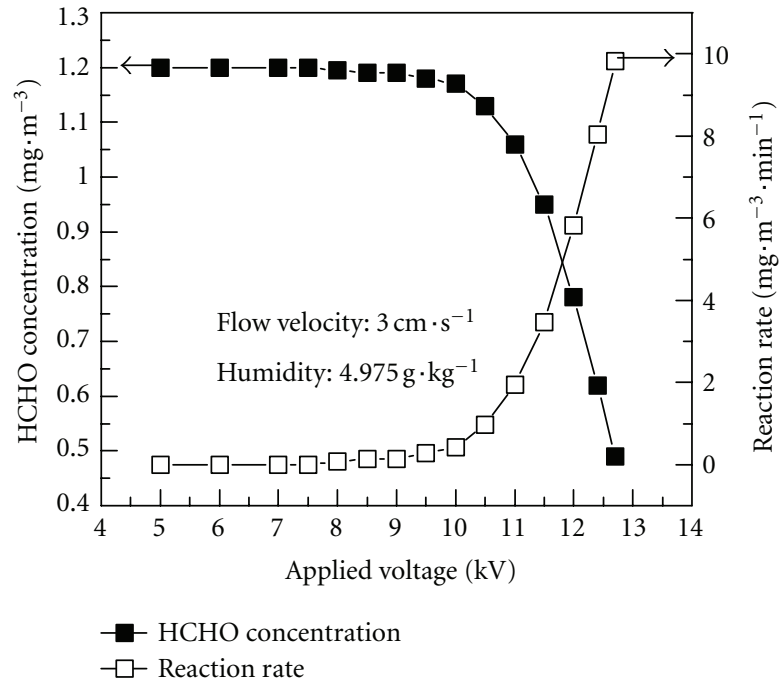

FIGURE 9: The removal of HCHO varies with the applied voltage.

Based on the above optimization results, the following study used the wire-to-pine discharge system to investigate the effect of applied voltage, flow velocity, and humidity on the removal of $\mathrm{HCHO}$.

3.2. Effect of Applied Voltage on the HCHO Removal. Figure 9 shows that the $\mathrm{HCHO}$ concentration and reaction rate vary with the applied voltage in the wire-to-plate electrode discharge system. In this paper, the reaction rate $\left(\mathrm{mg} /\left(\mathrm{m}^{3} \cdot \mathrm{min}\right)\right)$ is defined as [10]

$$
r=\frac{\left(C_{\text {in }}-C_{\text {out }}\right) Q}{V},
$$

where $Q$ is the flow rate of air stream $(\mathrm{mL} / \mathrm{min})$ and $V$ is the volume of photoreactor $(\mathrm{mL})$.

One can see that the HCHO concentration remained constant and the reaction rate of $\mathrm{HCHO}$ was zero when the applied voltage was small, which shows that there was not any NTP produced at small applied voltage. With the increase in applied voltage, the reaction rate of $\mathrm{HCHO}$ increased and the concentration of HCHO began to decrease. When the applied voltage reached breakdown voltage, the concentration of $\mathrm{HCHO}$ and reaction rate changed irregularly. Figure 9 only shows the result at the applied voltage that was less than breakdown voltage. It can be seen that the corona discharge was excited between wire and plate electrode when the applied voltage was larger than the exciting voltage, and corona discharge intensity enlarged when the applied voltage increased. As a result, a large amount of higher-energy plasmas produced, which collided with $\mathrm{HCHO}$ molecule and decomposed it. So the $\mathrm{HCHO}$ concentration decreased and the reaction rate increased with the increase in applied voltage. However, the applied voltage should not exceed the breakdown voltage to maintain high $\mathrm{HCHO}$ removal.

3.3. Effect of Flow Velocity on the HCHO Removal. Figure 10 shows the effect of flow velocity on the HCHO removal

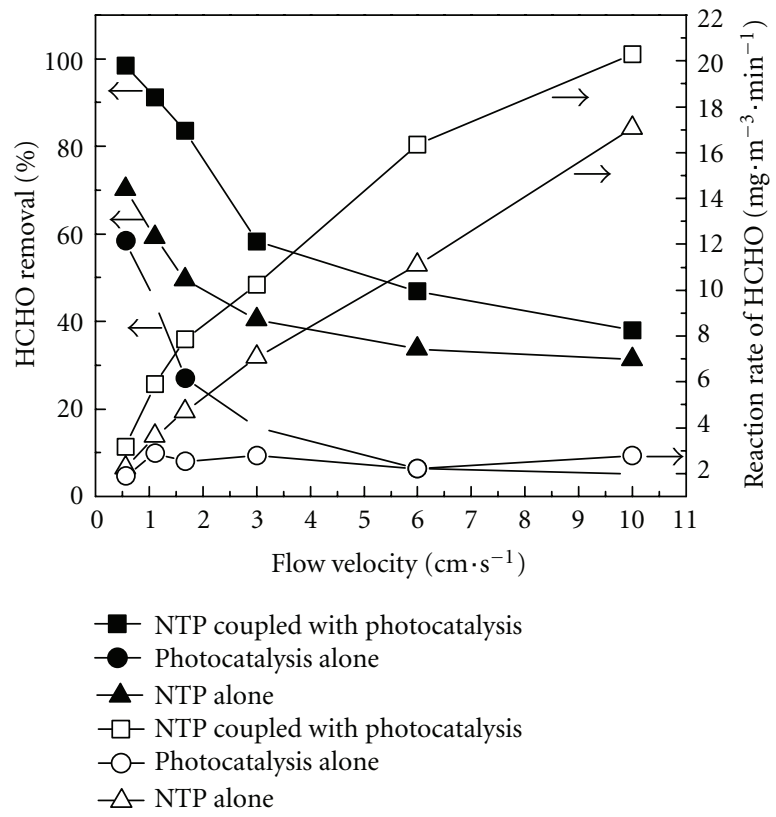

FIgure 10: The effect of flow velocity on the HCHO removal and reaction rate by different method.

and reaction rate by the different method with $\mathrm{HCHO}$ initial concentration of $1.18-1.24 \mathrm{mg} / \mathrm{m}^{3}$ at humidity level of $2.1 \mathrm{~g} / \mathrm{kg}$ (relative humidity, 18.8\%) and applied voltage of $11.5 \mathrm{kV}$. From Figure 10, we can see that HCHO removal decreased (but the reaction rate increased) with the increase in flow velocity. The HCHO removal and reaction rate were higher by the NTP method than those by the PCO. The reason is that the high-energy active species (atomic oxygen, hydroxyl radicals, ozone, etc.) generated in the NTP discharge process have stronger reactivity than the $\mathrm{HO}$ radical generated during the PCO process. So the $\mathrm{HCHO}$ was strongly oxidized by the NTP method. As a result, the combination of NTP with PCO enhanced the HCHO removal and reaction rate significantly.

In fact, for the photocatalytic removal of $\mathrm{HCHO}$, our study has found that the photocatalytic reaction rate first increased and then changed little with the increase in flow velocity, while the removal of $\mathrm{HCHO}$ decreased with it. The reason is that photocatalytic reaction took place from the diffusion control process to the photocatalytic reaction control process with the rise in flow velocity [12]. The same results marked by hollow and solid circles in Figure 10 were found again. However, for the removal of $\mathrm{HCHO}$ by the NTP method, the increase in flow velocity improved the reaction rate continuously with the applied voltage of $11.5 \mathrm{kV}$. It means that the number of NTPs is far greater than the HCHO molecules that collided with it. Therefore, the increase of flow velocity enhanced the diffusion of $\mathrm{HCHO}$ and resulted in the increase in reaction rate, which was consistent with reaction kinetics. So the reaction rate of $\mathrm{HCHO}$ by the NTP method was controlled by diffusion transfer. However, the removal of $\mathrm{HCHO}$ decreased with the increase in flow velocity for the predominant influence of residence time 
TABLE 1: The synergistic effect of NTP and PCO.

\begin{tabular}{|c|c|c|c|c|c|c|c|}
\hline Velocity $/(\mathrm{cm} / \mathrm{s})$ & & 0.56 & 1.11 & 1.67 & 3.0 & 6 & 10 \\
\hline \multirow{3}{*}{ Removal (\%) } & $\mathrm{PCO}$ & 58.4 & 44.4 & 27.0 & 15.8 & 6.3 & 5.2 \\
\hline & NTP & 70.2 & 59.2 & 45.6 & 40.5 & 33.6 & 31.4 \\
\hline & Both & 98.4 & 91.3 & 83.6 & 58.3 & 46.8 & 37.9 \\
\hline \multirow{3}{*}{ Reaction rate $\left(\mathrm{mg} / \mathrm{m}^{3} \cdot \mathrm{s}\right)$} & PCO & 1.87 & 2.87 & 2.54 & 2.77 & 2.21 & 2.77 \\
\hline & NTP & 2.23 & 3.64 & 4.69 & 7.06 & 11.1 & 17.1 \\
\hline & Both & 3.15 & 5.89 & 7.84 & 10.2 & 16.3 & 20.3 \\
\hline
\end{tabular}

reduced. The less residence time means that the collision probability of active species with $\mathrm{HCHO}$ gas from inlet to the outlet of the reactor decreased, while the amount of $\mathrm{HCHO}$ gas per unit time that collided with the plasma increased with the rise in flow velocity, which was coincident with the effect of flow velocity on the reaction rate. Comparing with the rise in reaction rate, the amount of pollutant needed to be cleaned increased quickly with the increase in flow velocity, so the removal of $\mathrm{HCHO}$ was higher at the lower flow velocity than that at the higher flow velocity due to the predominant influence of residence time.

Because the high energy plasma and the UV light emission from the association of the NTP can excite the $\mathrm{TiO}_{2}$ photocatalyst to produce the $\mathrm{HO}$ radical, which not only can enhance the oxidative ability of NTP but also can improve the photocatalytic ability of PCO, the combination of PCO with NTP shows the synergistic effect of both. As shows in Table 1, which is the same data as that in Figure 10, the $\mathrm{HCHO}$ removal (or reaction rate) by the combination of NTP with PCO was larger than its sum by PCO and by NTP with the rise in flow velocity. For example, $\mathrm{HCHO}$ removal was $37.4 \%$ at the flow velocity of $10 \mathrm{~cm} / \mathrm{s}$, which was larger than the sum of $5.2 \%$ by PCO and $31.4 \%$ by NTP. Also, the reaction rate of $20.3 \mathrm{mg} /\left(\mathrm{m}^{3} \cdot \mathrm{min}\right)$ by combination of NTP and PCO was larger than the sum of $2.77 \mathrm{mg} /\left(\mathrm{m}^{3} \cdot \mathrm{min}\right)$ by PCO and $17.1 \mathrm{mg} /\left(\mathrm{m}^{3} \cdot \mathrm{min}\right)$ by NTP. Therefore, the synergistic effects of PCO and NTP can obviously enhance the degradation of indoor pollutant. It can be seen that the synergistic effect mainly exists in the process that is controlled by photocatalytic reaction (as flow velocity is larger than $1.1 \mathrm{~cm} / \mathrm{s}$ ). It implies that the $\mathrm{TiO}_{2}$ photocatalyst activity was not fully excited by the UV light lamp in this paper during the process predominated by photocatalytic reaction when the flow velocity was larger than $1.1 \mathrm{~cm} / \mathrm{s}$. The combination of PCO with NTP excited the photocatalyst activity and resulted in the synergistic effect. When flow velocity was less than $1.1 \mathrm{~cm} / \mathrm{s}$, the photocatalytic reaction was controlled by diffusion process, during which the number of $\mathrm{HO}$ radical generated by $\mathrm{PCO}$ far outweighed the $\mathrm{HCHO}$ molecule that touched it, so the synergistic effect was not be manifested.

The above results proved again that the $\mathrm{HCHO}$ removal is controlled by the resident time of $\mathrm{HCHO}$ in the reactor, while the reaction rate is controlled by the diffusion of $\mathrm{HCHO}$. At the lower flow velocity, the resident time of $\mathrm{HCHO}$ in the reactor is higher, so the collision probability of $\mathrm{HCHO}$ with the active species is higher when the unit volume $\mathrm{HCHO}$ gas flows from the inlet to the outlet of the reactor. While the collision probability per unit time reduced at the lower flow velocity as the diffusion of $\mathrm{HCHO}$ was weak, this resulted in the decrease in reaction rate. At the higher flow velocity, the resident time was lower, while the collision probability per unit time was enhanced, so the $\mathrm{HCHO}$ removal decreased, but the reaction rate increased. For the practical indoor air purification, higher flow velocity and higher reaction rate can increase air treatment capacity and decrease air treatment time, which is very important for the practical application of air purification technology. It can be seen that the combination of PCO with NTP can improve the HCHO removal in higher flow velocity, which may be a route to purify the indoor pollutants.

3.4. Effect of Humidity on the HCHO Removal. For the photocatalytic oxidation of $\mathrm{HCHO}$, the bound molecular water on the surface of $\mathrm{TiO}_{2}$ will directly affect the production of the hydroxyl radical ( $\mathrm{HO})$. The ${ }^{\cdot} \mathrm{HO}$ is one of the most important oxidative species in the decomposing of $\mathrm{HCHO}$ for its higher oxidation potential $(2.8 \mathrm{eV})$. The primary reactions are given as follows:

$$
\begin{gathered}
\mathrm{TiO}_{2}+\mathrm{h} v \longrightarrow \mathrm{e}^{-}+\mathrm{h}^{+} \\
\mathrm{H}_{2} \mathrm{O}+\mathrm{h}^{+} \longrightarrow \mathrm{HO}+\mathrm{H}^{+} \\
\mathrm{OH}^{-}+\mathrm{h}^{+} \longrightarrow{ }^{\cdot} \mathrm{HO}
\end{gathered}
$$

So, a certain amount of water vapor benefits the removal of HCHO. However, the heavy or light water vapor on the catalyst surface will lead to the decrease in reaction rate. In the absence of water vapor, the production of the $\mathrm{HO}$ is limited, while excessive water vapor on the surface of $\mathrm{TiO}_{2}$ will occupy the active sites of reactants on the surface, which results in the competitive adsorption of water vapor and reactant on the $\mathrm{TiO}_{2}$ surface.

For the nonthermal plasma discharge, it has been observed that air humidity affects to a great extent the behaviors of coronas [24]. When a high voltage is applied to the anode (thin wire), electrons presented in the air move towards the anode and are ionized by collision, forming avalanches within the ionization zone around the anode. The ionization process in the gap is dependent on the field strength as well as the water vapor content in air. So the water vapor content controls the ionization process, which in turn controls the growth of the second generation of avalanches. The lower content of water vapor in air accelerates the collision of 


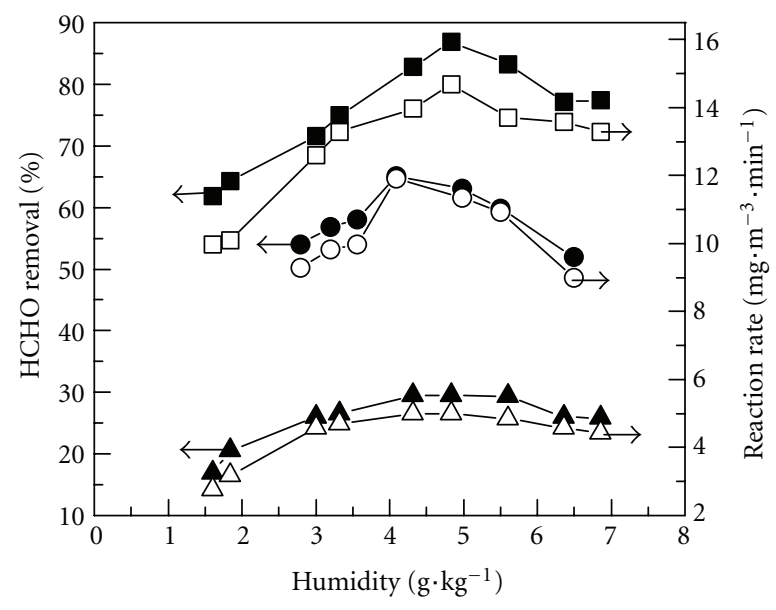

- Effect of NTP and PCO
- Effect of NTP
- Effect of PCO

$$
\begin{aligned}
& -\square-\text { Effect of NTP and PCO } \\
& -\bigcirc-\text { Effect of NTP } \\
& -\triangle \text { Effect of PCO }
\end{aligned}
$$

FIGURE 11: The effect of humidity on the removal and reaction rate of $\mathrm{HCHO}$ by different methods.

electron with water. As a result, the hydroxyl radical produces, which can oxidize the $\mathrm{HCHO}$ molecule touched with it. As the relative humidity increased, the thin water film formed on the surface of wire anode, which baffled the emission of photons from the primary avalanche. Therefore, the number of activated plasma decreased and the removal of $\mathrm{HCHO}$ reduced. Therefore, there exists the optimal humidity for the removal of HCHO by NTP discharge.

From the above analysis, it can be concluded that the effect of humidity on $\mathrm{HCHO}$ removal by combination of $\mathrm{PCO}$ with NTP should have the similar results. Figure 11 shows the effect of humidity on the $\mathrm{HCHO}$ removal and reaction rate by different methods with flow velocity of $3 \mathrm{~cm} / \mathrm{s}$ at the applied voltage of $11.5 \mathrm{kV}$. The similar results were obtained. The effect of humidity on $\mathrm{HCHO}$ removal and reaction rate had optimal value. The optimal humidity was about $4.1 \mathrm{~g} / \mathrm{kg}$ (relative humidity, $37.2 \%$ ) by NTP discharge, but $4.3 \mathrm{~g} / \mathrm{kg}$ (relative humidity $39.1 \%$ ) by PCO method, and about $4.8 \mathrm{~g} / \mathrm{kg}$ (relative humidity $43.4 \%$ ) by the combination of PCO with NTP. Because water vapor is the main substance for generating the active species during the degradation of $\mathrm{HCHO}$ by PCO (or by NTP), more water vapor is needed for $\mathrm{HCHO}$ removal by the combination of PCO with NTP. To the photocatalytic degradation of $\mathrm{HCHO}$, the effect of humidity on the reaction rate was not obvious after humidity was greater than the optimal value, which has been proved by our research group years ago [25], but it is clear by NTP discharge method. Therefore, for the HCHO removal by the combination of $\mathrm{PCO}$ with $\mathrm{NTP}$, the reaction rate increased quickly with the rise in humidity and reached the maximum at optimal humidity and decreased hereinafter. When the humidity was far above the optimal value, the effect of humidity on the $\mathrm{HCHO}$ removal was unobvious. The reason is that the excessive water can form competitive adsorption with $\mathrm{HCHO}$ on the $\mathrm{TiO}_{2}$ surface, but its influence is relatively small, so the photocatalytic reaction became the control process for HCHO removal when humidity was larger than the optimal value. From Figure 11, one can see that the $\mathrm{HCHO}$ removal was nearly $87 \%$ and the reaction rate was $14.7 \mathrm{mg} /\left(\mathrm{m}^{3} \cdot \mathrm{min}\right)$ at optimal humidity of $4.8 \mathrm{~g} / \mathrm{kg}$ by the combination of PCO with NTP. However, the optimal humidity is still lower than that that in common ambient conditions. Therefore, as a future method of indoor air purification application, it is needed to improve the $\mathrm{HCHO}$ removal at higher humidity conditions.

\section{Conclusions}

(1) The wire-to-plate configuration electrode system for producing NTP can be used in pollutant degradation for indoor air purification.

(2) The combination of PCO with NTP shows the synergistic effect for $\mathrm{HCHO}$ removal. When the photocatalytic reaction changed from the diffusion control process to the photocatalytic reaction control process with the increase in flow velocity, the synergistic effect became more and more obvious. So the combination of PCO and NTP might be a valid pathway to purify indoor air.

(3) The effects of humidity on the removal of $\mathrm{HCHO}$ by PCO, NTP discharge, or the combination of the both had an optimal humidity range. But the optimal humidity was lower than that in the common ambient conditions. Therefore, it is needed to try to redesign the reactor so as the combination of NTP with PCO can work effectively in a higher humidity range.

\section{Acknowledgments}

This project was supported by the National Natural Science Foundation (50476036), National Basic Research Program of China (2012CB720106), and the Open Foundation of the Key Laboratory of Heat Transfer and Energy Conversion, Beijing Municipality, Beijing University of Technology.

\section{References}

[1] A. Fujishima and K. Honda, "Electrochemical photolysis of water at a semiconductor electrode," Nature, vol. 238, no. 5358, pp. 37-38, 1972.

[2] S. B. Kim and S. C. Hong, "Kinetic study for photocatalytic degradation of volatile organic compounds in air using thin film $\mathrm{TiO}_{2}$ photocatalyst," Applied Catalysis B, vol. 35, no. 4, pp. 305-315, 2002.

[3] S. B. Kim, H. T. Hwang, and S. C. Hong, "Photocatalytic degradation of volatile organic compounds at the gas-solid interface of a $\mathrm{TiO}_{2}$ photocatalyst," Chemosphere, vol. 48, no. 4, pp. 437-444, 2002.

[4] L. Zhao, J. Ran, Z. Shu et al., "Effects of calcination temperatures on photocatalytic activity of ordered titanate nanoribbon $/ \mathrm{SnO}_{2}$ films fabricated during an EPD process," International Journal of Photoenergy, vol. 2012, Article ID 472958, 7 pages, 2012. 
[5] J. Yu, J. C. Yu, M. K. P. Leung et al., "Effects of acidic and basic hydrolysis catalysts on the photocatalytic activity and microstructures of bimodal mesoporous titania," Journal of Catalysis, vol. 217, no. 1, pp. 69-78, 2003.

[6] J. Gamage and Z. Zhang, "Applications of photocatalytic disinfection," International Journal of Photoenergy, vol. 2010, Article ID 764870, 11 pages, 2010.

[7] J. Yu, S. Liu, and H. Yu, "Microstructures and photoactivity of mesoporous anatase hollow microspheres fabricated by fluoride-mediated self-transformation," Journal of Catalysis, vol. 249, no. 1, pp. 59-66, 2007.

[8] J. A. Byrne, P. A. Fernandez-Ibañez, P. S. M. Dunlop, D. M. A. Alrousan, and J. W. J. Hamilton, "Photocatalytic enhancement for solar disinfection of water: a review," International Journal of Photoenergy, vol. 2011, Article ID 798051, 2008.

[9] J. Yu, G. Wang, B. Cheng, and M. Zhou, "Effects of hydrothermal temperature and time on the photocatalytic activity and microstructures of bimodal mesoporous $\mathrm{TiO}_{2}$ powders," Applied Catalysis B, vol. 69, no. 3-4, pp. 171-180, 2007.

[10] J. G. Yu, T. T. Ma, and S. W. Liu, "Enhanced photocatalytic activity of mesoporous $\mathrm{TiO}_{2}$ aggregates by embedding carbon nanotubes as electron-transfer channel," Physical Chemistry Chemical Physics, vol. 13, no. 8, pp. 3491-3501, 2011.

[11] C. H. Ao and S. C. Lee, "Indoor air purification by photocatalyst $\mathrm{TiO}_{2}$ immobilized on an activated carbon filter installed in an air cleaner," Chemical Engineering Science, vol. 60, no. 1, pp. 103-109, 2005.

[12] Y. Lu, D. Wang, and C. Ma, "The effect of activated carbon adsorption on the photocatalytic removal of formaldehyde," Building and Environment, vol. 45, no. 3, pp. 615-621, 2010.

[13] P. Chin, L. P. Yang, and D. F. Ollis, "Formaldehyde removal from air via a rotating adsorbent combined with a photocatalyst reactor: kinetic modeling," Journal of Catalysis, vol. 237, no. 1, pp. 29-37, 2006.

[14] C. H. Ao and S. C. Lee, "Enhancement effect of $\mathrm{TiO}_{2}$ immobilized on activated carbon filter for the photodegradation of pollutants at typical indoor air level," Applied Catalysis B, vol. 44, no. 3, pp. 191-205, 2003.

[15] C. H. Ao and S. C. Lee, "Combination effect of activated carbon with $\mathrm{TiO}_{2}$ for the photodegradation of binary pollutants at typical indoor air level," Journal of Photochemistry and Photobiology A, vol. 161, no. 2-3, pp. 131-140, 2004.

[16] C. H. Ao, S. C. Lee, J. Z. Yu, and J. H. Xu, "Photodegradation of formaldehyde by photocatalyst $\mathrm{TiO}_{2}$ : effects on the presences of $\mathrm{NO}, \mathrm{SO}_{2}$ and VOCs," Applied Catalysis B, vol. 54, no. 1, pp. 41-50, 2004.

[17] C. H. Ao and S. C. Lee, "Indoor air purification by photocatalyst $\mathrm{TiO}_{2}$ immobilized on an activated carbon filter installed in an air cleaner," Chemical Engineering Science, vol. 60, no. 1, pp. 103-109, 2005.

[18] C. H. Ao, S. C. Lee, C. L. Mak, and L. Y. Chan, "Photodegradation of volatile organic compounds (VOCs) and NO for indoor air purification using $\mathrm{TiO}_{2}$ : promotion versus inhibition effect of NO," Applied Catalysis B, vol. 42, no. 2, pp. 119-129, 2003.

[19] L. U. Yuanwei, L. I. Wencai, W. Wang, and C. Ma, "Combination of activated carbon with $\mathrm{TiO}_{2}$ for the photodegradation of indoor formaldehyde(I)," Acta Energiae Solaris Sinica, vol. 29, no. 1, pp. 114-118, 2008 (Chinese).

[20] L. U. Yuanwei, L. I. Wencai, W. Wang, and C. Ma, "Combination of activated carbon with $\mathrm{TiO}_{2}$ for the photodegradation of indoor formaldehyde(II)," Acta Energiae Solaris Sinica, vol. 29, no. 5, pp. 550-554, 2008 (Chinese).
[21] C. Subrahmanyam, M. Magureanu, A. Renken, and L. KiwiMinsker, "Catalytic abatement of volatile organic compounds assisted by non-thermal plasma-part 1: a novel dielectric barrier discharge reactor containing catalytic electrode," Applied Catalysis B, vol. 65, no. 1-2, pp. 150-156, 2006.

[22] T. Yamamoto, K. Mizuao, I. Tamori et al., "Catalysis-assisted plasma technology for carbon tetrachloride destruction," IEEE Transactions on Industry Applications, vol. 32, no. 1, pp. 100105, 1996.

[23] J. Van Durme, J. Dewulf, W. Sysmans, C. Leys, and H. Van Langenhove, "Efficient toluene abatement in indoor air by a plasma catalytic hybrid system," Applied Catalysis B, vol. 74, no. 1-2, pp. 161-169, 2007.

[24] L. Fouad and S. Elhazek, "Effect of humidity on positive corona discharge in a three electrode system," Journal of Electrostatics, vol. 35, no. 1, pp. 21-30, 1995.

[25] M. Chang, The study of the performance evaluation for photocatalytic indoor air purification, M.S. thesis, University of Technology, Beijing, China, 2005. 


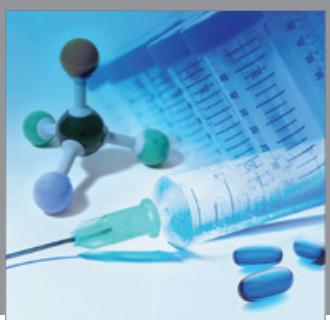

International Journal of

Medicinal Chemistry

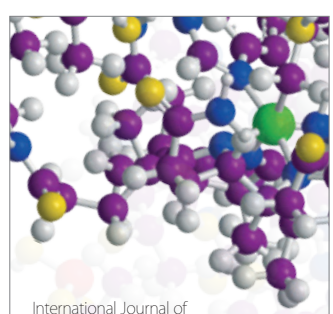

Carbohydrate Chemistry

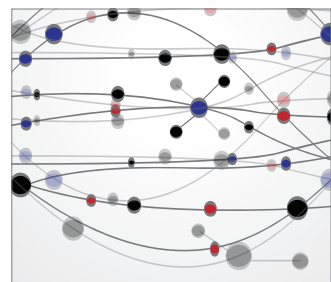

The Scientific World Journal
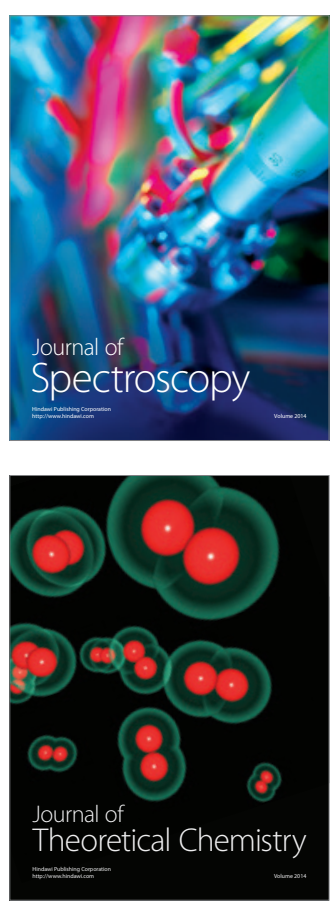
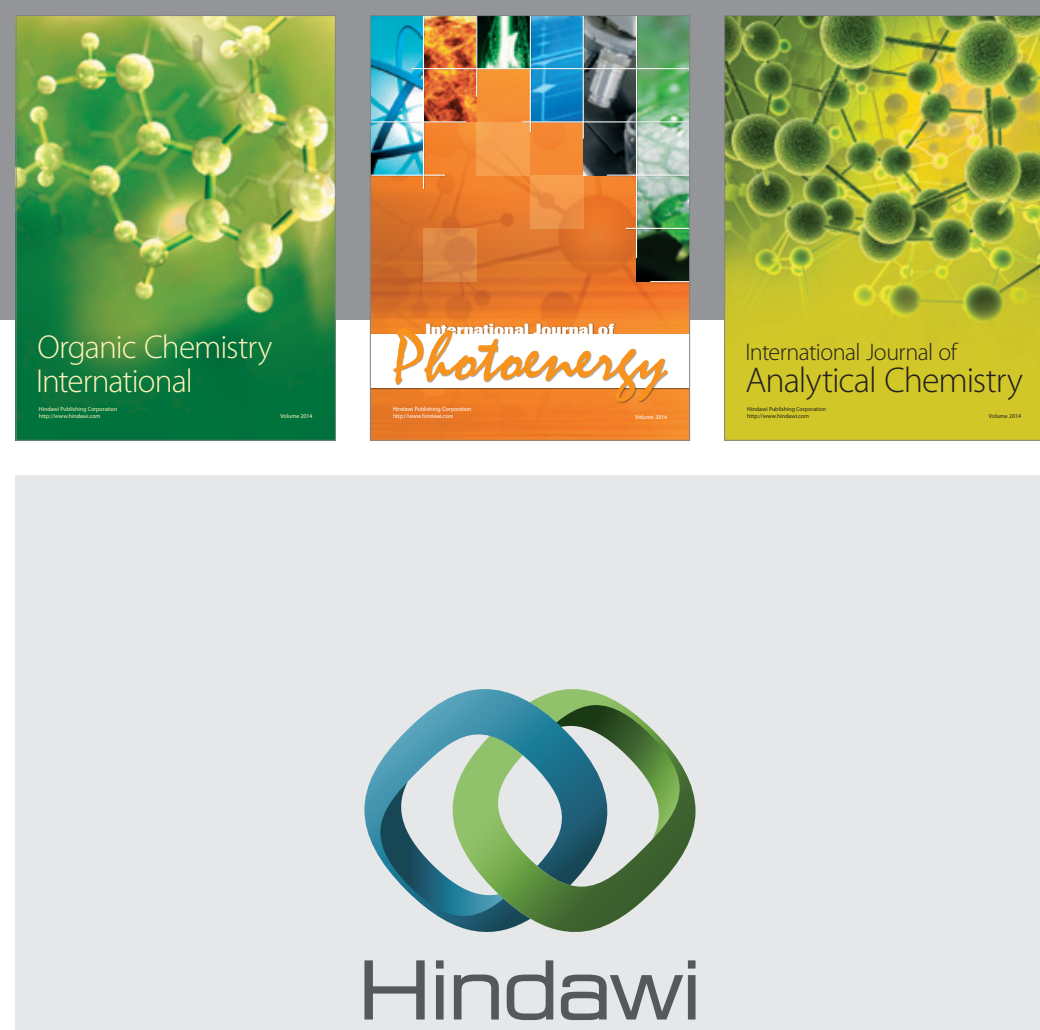

Submit your manuscripts at

http://www.hindawi.com
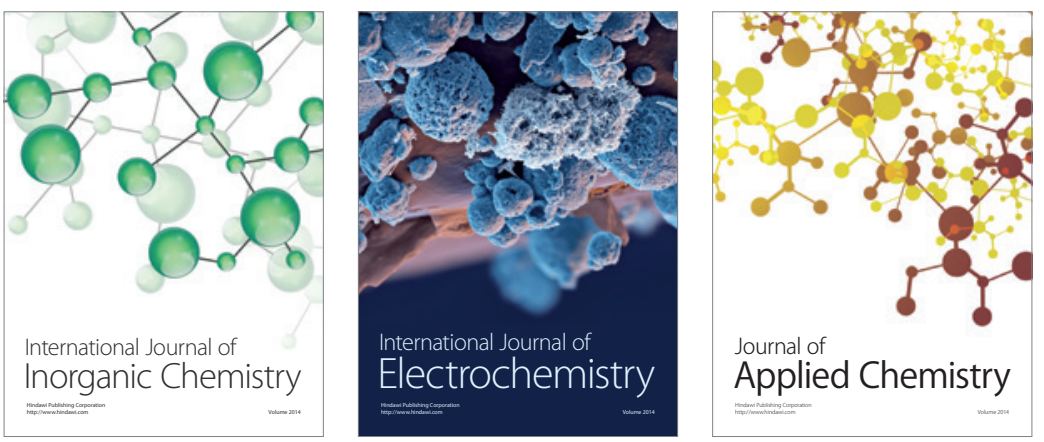

Journal of

Applied Chemistry
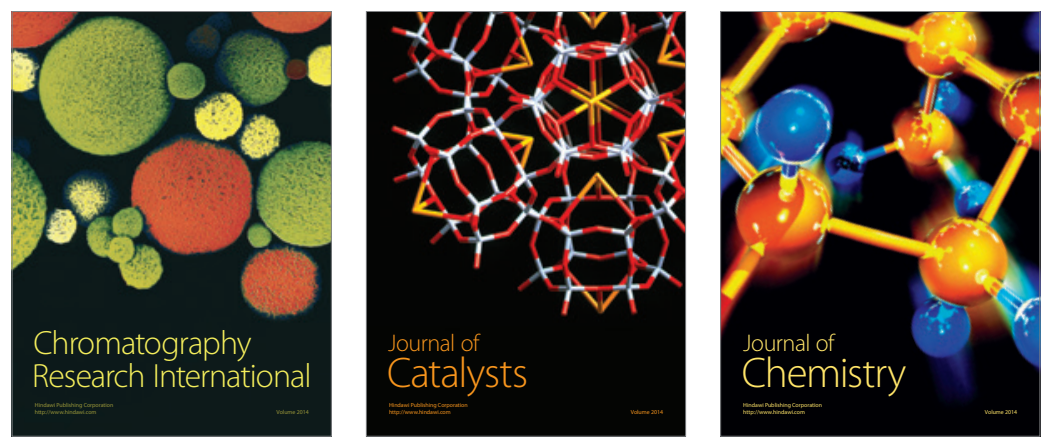
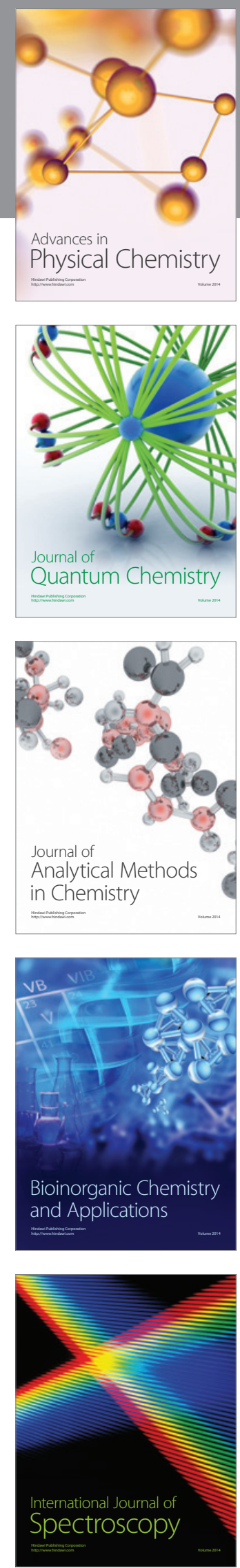